\title{
THE FORMATION OF BUBBLES IN Zr ALLOYS UNDER Kr ION IRRADIATION*
}

\author{
R. C. Birtcher \\ Materials Science Division \\ Argonne National Laboratory \\ Argonne, II 60439 \\ L. Pagano, Jr., and A.T. Motta \\ Department of Nuclear Engineering \\ The Pennsylvania State University \\ University Park, PA 16802-1408
}

June 1996

\begin{abstract}
The submitted manuscript has been created by the University of Chicago as Operator of Argonne National Laboratory ("Argonne") under Contract No. W-31-109-ENG-38 with the U.S. Department of Energy. The U.S. Government retains for itself, and others acting on its behalf, a paid-up, nonexclusive, irrevocable worldwide license in said article to reproduce, prepare derivative works, distribute copies to the public, and perform pub. licly and display publicly, by or on behalf of the Government.
\end{abstract}

\section{DISTRIBUTION OF THIS DOCUMENT IS UNLIMITED $2 \mathrm{~g}$}

\section{PROCESSED FROMA BEST AVAILABLE COPY H Hie}

Abstract submitted to the Annual TMS (The Minerals, Metals and Materials Society) Meeting in Anaheim, CA, February 4-8, 1996.

*Work supported by the U. S. Department of Energy, BES-Materials Sciences, under Contract W-31-109-Eng-38.

\section{DISCLAIMER}




\section{DISCLAIMER}

Portions of this document may be illegible in electronic image products. Images are produced from the best available original document. 


\title{
The Formation of Bubbles in $\mathrm{Zr}$ Alloys under $\mathrm{Kr}$ ion irradiation
}

\author{
L. Pagano, Jr., A.T. Motta*, \\ Department of Nuclear Engineering \\ The Pennsylvania State University \\ University Park, PA 16802-1408
}

and

R.C. Birtcher

Materials Science Division,

Argonne National Laboratory

Argonne IL, 60439

\begin{abstract}
We report here a study of $\mathrm{Kr}$ ion implantation and the resultant bubble formation in $\mathrm{Zr}$ and $\mathrm{Zr}$ alloys, including Zircaloy-2 and Zircaloy-4. Implantations into thin foils were performed in the HVEM/Tandem facility at Argonne National Laboratory at temperatures between 300 to $800 \mathrm{C}$ and to doses up to $2 \times 10^{16}$ ion.cm ${ }^{-2}$. Bulk specimens were implanted in an ion-beam chamber and then thinned for viewing by TEM. In thin foils, only small bubbles (30-100 $\AA$ ) were formed at all temperatures with the exception of the $\mathrm{Cr}$-rich Valloy where bubbles of $130 \AA$ bubbles were formed. Bulk samples implanted at $300 \mathrm{C}$ contained a bubble morphology similar to that observed after implantation into thin foils. However at high temperatures (500-800 C) large faceted bubbles (up to $300 \AA$ ) were produced in bulk specimens. The results indicate that bubble
\end{abstract}


formation and evolution below $500 \mathrm{C}$ is controlled by gas concentration, while it is controlled by bubble mobility at high temperatures.

\section{Introduction}

One of the properties of $\mathrm{Zr}$ alloys that has made them very attractive for use in nuclear power applications is their remarkable resistance to void swelling during reactor-neutron irradiation [1]. In contrast to other metals and to other alloys used for nuclear fuel cladding, such as stainless steel, $\mathrm{Zr}$ and $\mathrm{Zr}$ alloys exhibit little void formation and, as a consequence, little swelling when exposed to irradiation.

The few examples of radiation-induced cavities in $\mathrm{Zr}$ alloys have generally involved the irradiation of samples pre-implanted with insoluble noble gases such as $\mathrm{He}$ and $\mathrm{Ne}[2,3]$. Zirconium is peculiar in that both vacancy and interstitial loops are stable under irradiation (usually one type grows at the expense of the other). When only interstitial loops are present voids can grow by absorbing excess vacancies. The vacancy loops represent an alternative route to voids for the evolution of small vacancy clusters. The insoluble gases negate this route, by stabilizing small void embryos against collapse to vacancy loops [4]. The anisotropic nature of $\mathrm{Zr}$

also causes it to behave differently from cubic materials under irradiation. In particular, the defect migration energies in the $<c>$ and $<a>$ directions are different. This migration anisotropy is linked to the presence of trace $\mathrm{Fe}$ in the $\mathrm{Zr}$ matrix [5].

The formation of voids under irradiation have been observed in a large number of metals and alloys [6]. Void formation is made possible by the establishment of a high supersaturation of point defects under irradiation. The constant production and annihilation of defects, especially 
vacancies, can promote the nucleation and growth of voids and bubbles. For voids to grow in metals during irradiation they must receive a net flux of vacancies to voids. This means that interstitials, (produced in equal numbers by irradiation), must be preferentially absorbed in other sinks in the microstructure of the material.

Extensive evidence of void formation in metals has accumulated over the past decades $[6,7]$. Notably, a few elements $(\mathrm{Zr}, \mathrm{Ti})$ have shown a remarkable resistance to void formation [8]. Studies have been performed of void formation in $\mathrm{Zr}$ and $\mathrm{Zr}$ alloys under both neutron [9-11] and charged particle irradiation [12-14]. Examination of neutron-irradiated Zircaloy has occasionally revealed cavities especially after high fluences, when, presumably, enough He has been produced by $(n, \alpha)$ reactions. Gilbert et al. [9] identified the few cavities they observed in Zircaloy after neutron irradiation to $10^{25}$ $n . m^{-2}(E>0.1 \mathrm{MeV})$ as equilibrium gas bubbles. The work of Buckley and Manthorpe [12] showed that voids are formed in zirconium during electron irradiation, and the maximum swelling occurs at $450-500 \mathrm{C}$. They also found that voids grew more readily in samples that had been previously doped with $10^{-5} \mathrm{Xe}$ than in undoped samples. However their experiments were influenced by bad vacuum conditions in the microscope during irradiation. Jostsons et al. [10 ] found voids in pure $\mathrm{Zr}$ neutron-irradiated to $1.3 \times 10^{21}$ n. $\mathrm{cm}^{-2}$ only in the temperature range 400 to $500 \mathrm{C}$, and only in the samples that had the highest B content (1 ppm). Faulkner and Woo [13] studied void swelling in zirconium under electron irradiation and found that the pre-injection of He was essential for void development. Specimens implanted with $100 \mathrm{ppm}$ He developed voids while those implanted with $10 \mathrm{ppm}$ or less did not. Their maximum swelling temperature of $450 \mathrm{C}$ 
agrees well with the results from Jostsons et al and Buckley and Manthorpe. Finally it has recently been demonstrated that electron irradiation to $50-70 \mathrm{dpa}$ at $500 \mathrm{C}$ creates cavities in Zircaloy previously irradiated with neutrons, $\left(0.2 \times 10^{25} \mathrm{n} \cdot \mathrm{m}^{-2}\right)$ [14].

The study of void formation in other metals has advanced considerably in recent years [15]. Implantation of noble gases into metals such as $\mathrm{Al}[16,17], \mathrm{Ni}[18,19], \mathrm{Ti}[20]$ and $\mathrm{Mo}$ [21] results in the formation of solid noble gas precipitates. These solid precipitates form inside very high pressure bubbles. As the bubble or solid precipitate grows the precipitate melts and the bubbles become mobile leading to coalescence and rapid bubble growth. During $\mathrm{Kr}$ implantation of $\mathrm{Ni}, \mathrm{Birtcher}$ and Liu [18] observed that, as the temperature increased, a bimodal bubble distribution appeared, which coincided with the disappearance of the solid $\mathrm{Kr}$ diffraction spots. Other studies have shown void lattice formation in different metals [22].

Such systematic studies have not been performed for $\mathrm{Zr}$. We have in this work conducted a systematic study of the conditions of bubble formation in zirconium alloys under $\mathrm{Kr}$ ion irradiation. The objective was to determine the temperature regime where bubble mobility results in the formation of larger bubbles. A second goal was to derive mechanistic understanding of the process of bubble formation and growth in zirconium alloys during implantation.

\section{Experimental Methods}

This work consisted of two distinct types of specimens denoted "thin foil" and "bulk" that were used for either in-situ or ex-situ implantations. The implantations were performed in the HVEM/Tandem User Facility at Argonne National Laboratory (ANL) using a $650 \mathrm{keV}$ NEC ion implanter. Implantations were done either "in-situ" with the sample placed in a TEM specimen 
holder in the High Voltage Electron Microscope, or in an ion-beam specimen chamber. The vacuum in the HVEM and in the accelerator target line was $1-2 \times 10^{-7}$ torr. Samples were examined before and after irradiation in the Phillips EM420 in the Materials Characterization Laboratory (MCL) at Pennsylvania State University (PSU), and on the JEOL 100CX at ANL. $\mathrm{Zr}$ alloys were furnished by General Electric. Their composition is shown in Table 1. For the "thin foil" experiments, $3 \mathrm{~mm}$ diameter, $0.1 \mathrm{~mm}$ thickness disks were prepared by cutting and mechanical polishing. Transmission Electron Microscopy (TEM) samples were made by electropolishing in a solution of $10 \%$ perchloric acid in methanol, kept at $-40^{\circ} \mathrm{C}$, or in a solution of $5.3 \mathrm{~g} \mathrm{LiCl}, 11.16 \mathrm{~g} \mathrm{Mg}\left(\mathrm{ClO}_{4}\right)_{2}, 500 \mathrm{ml}$ methanol and $100 \mathrm{ml}$ butyl solve kept at $-50 \mathrm{C} \mathrm{[23].}$ These samples were then irradiated with $100 \mathrm{keV} \mathrm{Kr}$ ions to fluences up to $2 \times 10^{16}$ $\mathrm{Kr} / \mathrm{cm}^{2}$. The $\mathrm{Kr}$ ion distribution and displacement rate in $\mathrm{Zr}$ as calculated by TRIM [24], is shown in Figure 1. The peak in the ion concentration occurs at a depth of $360 \AA$ while the displacement peak occurs at $200 \mathrm{~A}$. The width of the concentration peak is narrow enough that most of the gas is deposited within a $1000 \AA$ foil. The level of damage calculated by TRIM at the half maximum of the Bragg peak was $1 \mathrm{dpa}$ per $4.4 \times 10^{14}$ ion. $\mathrm{cm}^{-2}$, using $\mathrm{E}_{\mathrm{d}}=25 \mathrm{eV}$. The peak damage level at $2 \times 10^{16}$ ion. $\mathrm{cm}^{-2}$ corresponds thus to $45 \mathrm{dpa}$. The peak $\mathrm{Kr}$ concentration in the $10 \mathrm{~A}$ around the peak is 9 atom \%. The bulk irradiations were conducted in the same fashion, except that the samples were thinned after implantation by covering the implanted face with lacquer and thinning from the other side.

A bright field TEM micrograph of the microstructure of nominally pure $\mathrm{Zr}$ is shown in Figure 2; a fully recrystallized structure was obtained, with large equiaxed grains, and low dislocation density. The samples pre-thinned before irradiation had an overall thickness of 1000 - 
$1500 \AA$ in the electron thin areas, while the bulk samples had a thickness of $1 \mathrm{~mm}$. Although in the bulk samples the implantation is also done within $350 \AA$ of the free surface, there is only one free surface close to the irradiated area, as compared to two in the thin foil case. This difference is important as will be seen below.

Irradiations of Zircaloy-4 were made for all the irradiation conditions used (bulk and thin foil implanting, temperatures from 300-800 C, and fluences of $\left.1-2 \times 10^{16} \mathrm{ion} \cdot \mathrm{cm}^{-2}\right)$, and all the alloys in table 1 for thin foil irradiation at $300-700^{\circ} \mathrm{C}$ to $2 \times 10^{16}$ ion. $\mathrm{cm}^{-2}$.

\section{Results}

Figure 3 shows overfocus/underfocus pairs taken from thin foil Zircaloy- 4 specimens, at temperatures ranging from 300 to $800^{\circ} \mathrm{C}$ to a dose of $2 \times 10^{16}$ ion.cm $\mathrm{cm}^{-2}$. An even distribution of small bubbles is seen. No bubbles at grain boundaries were observed. During the in-situ implantation, the bubble concentration appeared to saturate well before the dose of $2 \times 10^{16}$ ion.cm ${ }^{-2}$. This effect occurred for all the alloys and for pure $\mathrm{Zr}$. A typical bubble size distribution for pure $\mathrm{Zr}$ is shown in Figure 4; some evidence of bubble algnment can also be seen. Although we expected that some of those small bubbles would be solid, no extra electron diffraction spots from solid $\mathrm{Kr}$ were found and therefore no evidence of solid bubbles was obtained.

Bulk Zircaloy-4, implanted to a dose of at $2 \times 10^{16} \mathrm{ion} / \mathrm{cm}^{2}$, exhibits a markedly different type of behavior, Figure 5a. The bubble distribution after implantation at $300^{\circ} \mathrm{C}$ was similar to that found in a "thin foil" irradiation, but implanting at 500 and $700^{\circ} \mathrm{C}$ resulted in much larger faceted bubbles Figure 5 b. At $500 \mathrm{C}$ bubbles even small bubbles were faceted, indicating good atomic surface mobility. The bubble sizes at $700^{\circ} \mathrm{C}$ (fig.5c) were quite large and bubble coalescence was 
observed, indicating that bubbles were mobile at that temperature. At $700 \mathrm{C}$ a higher concentration of bubbles near grain boundaries was also seen (Figure 6). Bubbles at the grain boundaries are no longer faceted and are approximately twice as big as the bubbles within the grain.

A TEM image of bulk Zircaloy-4 implanted to a dose of $2 \times 10^{16}$ ion. $\mathrm{cm}^{-2}$ at $800 \mathrm{C}$ is shown in Figure 7. Evidence of a significant amount of bubble coalescence is seen in Figure 7, as well as bubble faceting. After this irradiation at $800 \mathrm{C}$, we observed plate-like precipitates, shown in low magnification bright-field in Figure 8, and in dark-field in figure 9. These are likely hydrides or oxides, which formed on the specimen free surface during this irradiation. We believe this to be an artifact, possibly related to vacuum conditions at the time of the experiment. Compositional analysis of the precipitates by EDX revealed that they were not enriched in any of the Zircaloy-4 alloying elements ( $\mathrm{Sn}, \mathrm{Fe}, \mathrm{Cr}, \mathrm{Ni}$ ), and that there was only a slight increase in the $\mathrm{Kr}$ concentration. Diffraction patterns from the precipitate were not identified. Interestingly, the $\mathrm{Kr}$ bubble distribution was different under (or in) the precipitates than in-between precipitates. The bubble size distributions for both "under" and "between" precipitates is shown in Figure 10. The distribution of large-size bubbles was the same, but the region under the precipitates contained a large density of small $(60 \AA)$ bubbles (region marked "A" in figure 7), which was absent between precipitates (region marked " $\mathrm{B}$ " in figure 7). It is possible that the precipitates made it more difficult for the gas to leave the thin foil.

There was little effect of alloy type on the bubble size distributions for "thin foil" experiments from 300-700 $\AA$. The only exception was Valloy where some larger bubbles (100$130 \AA$ ) were seen in clusters (Figure 11) 
A summary of bubble size distributions is shown in Figures 12 and 13. The difference between "thin foil" and "bulk" irradiation is clearly seen, as is the effect of $\mathrm{Kr}$ fluence. Figure 12 shows the change in bubble size distribution for Zircaloy- 4 as a function of irradiation conditions at temperatures ranging from 300 to $800 \mathrm{C}$ (bulk irradiations at 300 and $500 \mathrm{C}$ are not plotted in this graph). The extension of the bubble distribution to larger sizes in bulk specimens at 700 and $800 \mathrm{C}$ is clearly visible. The thin foil irradiations by contrast produce only small bubbles. Figure 13 shows the bubble size distribution from thin foil irradiations of the different alloys. With the exception of Valloy, which shows a small number of bubbles with diameters in the 10-12 nm range, the bubbles in these samples were all in the $3-8 \mathrm{~nm}$ range, regardless of the irradiation temperature within the range $300-700 \mathrm{C}$.

Figure 14 shows the maximum bubble size against temperature for "thin foil" and "bulk" specimens of Zircaloy-4. These were obtained by examining several prints at different tilts to identify the largest bubble diameter for each temperature. The peak diameter is relatively independent of temperature for thin foil specimens while it increases markedly with temperature for the bulk specimens. These results are discussed in the next section.

\section{Discussion}

One of the main points in this work is that the temperature at which the maximum bubble size is observed is much higher than previously reported. Faulkner and Woo observed a maximum void swelling under neutron irradiation at $450^{\circ} \mathrm{C}$, whereas in the present work the cavities at $800^{\circ} \mathrm{C}$ were clearly bigger than those at $500^{\circ} \mathrm{C}$. The results of Buckley and Manthorpe 
also show a peak in swelling between $400-500^{\circ} \mathrm{C}$ during electron irradiation of thin specimens of pure $\mathrm{Zr}$.

An additional difference in our work from that of Faulkner and Woo [13] is that they found voids during irradiation of thin foils, while we did not. The difference is likely due to their pre-implantation of $100 \mathrm{ppm} \mathrm{He}$ as a void stabilizer during electron irradiation, while we used $\mathrm{Kr}$ to both stabilize the cavities and to produce displacement damage. An additional possible explanation for the difference could be $\mathrm{Kr}$ bubbles become mobile and coalesce at a higher temperature voids or dilute He bubbles.

We attempted to account for the implanted $\mathrm{Kr}$ through use of Ronchi's equation of state for rare-gas bubbles in solids [25] and assuming that the bubbles were at equilibrium cavity pressures. Ronchi's equation is given by:

$$
p \frac{V}{N R T}=F(r)
$$

where $p$ is the bubble pressure, $V$ is the volume, $T$ is the temperature and $N$ is the number of gas atoms, $R$ is the gas constant and $r$ is the radius. The function $F(r)$ is calculated and presented in tabular form in reference 25 . Using the bubble distributions shown in figures $10,12-14$, we calculated the total number of gas atoms in each size from equation 1, assuming they are equilibrium bubbles. The amount of $\mathrm{Kr}$ retained in bulk specimens is approximately $70 \%$ while in thin foils it less than 5\%. This supports the theory that the difference between the thin foil and bulk cases is due to $\mathrm{Kr}$ gas, either in the form of bubbles or atomic $\mathrm{Kr}$, escaping through the surfaces during thin foil implantation. 


The different temperature regimes can be summarized as in the following. At low temperatures, bubbles are immobile and at high pressures, possibly close to that required to solidify the Kr. Bubbles growth is gas-driven, controlled by the steady state gas concentration. At higher temperatures, very small bubbles are immobile, either because they are solid or because of high pressure [26]. As bubble size increases, the pressure decreases and at a critical bubble radius they become mobile (possibly associated with $\mathrm{Kr}$ melting). When bubbles become mobile, they can coalesce with other bubbles or leave the specimen through a nearby surface. Mobile bubbles in thin specimens are much more likely to reach a free surface than those migrating in bulk material, where they have some probability of moving away from the free surface. Thus bubble . coalescence is much more likely in bulk specimens than in thin foils. As the bubbles grow, their mobility decreases [26]: depending on the atomic transport mechanism, the bubble diffusion coefficient is proportional to $1 / \mathrm{r}^{\mathrm{n}}$, with $\mathrm{n}=2,3$ or 4 , and where $\mathrm{r}$ is the bubble radius. Regardless of the model for bubble migration, if the bubble mean free path and lifetime are long enough, a bubble will grow to a point when it is effectively immobilized. This will result in a much higher proportion of the implanted gas being retained in bulk specimens.

Part of the difference between thin foil and bulk irradiation may be attributed to $\mathrm{Kr}$ and possibly vacancy loss to free surfaces. Similar results were attained for thin specimens implanted in both the HVEM and in the ion chamber indicating that the effect was not related to the vacuum conditions, dosimetry or temperature control. This interpretation is supported by enhanced bubble growth in the presence of plate-like surface precipitates. When the precipitates were present, the $\mathrm{Kr}$ loss to the foil surface was likely suppressed, thereby increasing the total amount condensed into bubbles. 
The increase with temperature in the peak bubble size indicates when $\mathrm{Kr}$ bubbles become mobile and coalesce. This occurs at a much higher temperature than the previously reported peak swelling during neutron and electron irradiation of $\operatorname{Zr}[10,12,13]$. This may be an indication of the different nature of the two processes: void swelling being controlled by vacancy migration, and the gas swelling determined by gas and bubble migration. If void swelling occurs by a mechanism of He-assisted nucleation followed by void growth from vacancy absorption, then the activation energy would correspond to the vacancy migration. If the formation of large bubbles is controlled by bubble coalescence, it would not be surprising that it occurs at a different temperature.

Another surprising result of this work is that there is little difference in bubble sizes in the different materials implanted. In particular, there was no difference between nominally pure $\mathrm{Zr}$ and the $\mathrm{Zr}$ alloys. Since alloying elements have been shown to influence defect diffusion [5], and void formation [12], this result was unexpected. This absence of effect may be due to the use of thin specimens. The presence of the nearby surface sinks in these experiments may overwhelm all other processes, thereby masking any possible differences in migration between the different alloys.

\section{Conclusions}

A systematic study was conducted of bubble formation in $\mathrm{Zircaloy}-4$ and other $\mathrm{Zr}$ alloys under $\mathrm{Kr}$ ion irradiation. The main conclusions of this study are:

1. Bubbles form in all alloys, at all temperatures and implantation geometries studied. This is in agreement with previous results that show that cavity formation in $\mathrm{Zr}$ alloys under irradiation is greatly enhanced by the presence of noble gases. 
2. The bubble sizes observed in bulk samples were considerably larger than in thin samples. This is attributed to the greater loss of gas atoms and of vacancies to the surface in the thin foil case.

3. In the bulk Zircaloy-4 samples, bubble size increased with irradiation temperature. The maximum bubble diameter within the grains increased from $10 \mathrm{~nm}$ at $300 \mathrm{C}$ to $40 \mathrm{~nm}$ at $800 \mathrm{C}$. Above $700 \mathrm{C}$ large faceted bubbles and bubble coalescence were found. This indicates that $\mathrm{Kr}$ bubbles are mobile in Zircaloy at temperatures above $700 \mathrm{C}$.

4. For the thin specimens, bubble size did not depend on implantation temperature, in the temperature range $300-700 \mathrm{C}$. The bubble morphology was similar to that observed in bulk specimens implanted at $300 \mathrm{C}$, and corresponded to a low temperature gas-driven regime.

5. The gas retained, using Ronchi's equation of state and assuming equilibrium bubble pressures, was much higher in bulk samples than in pre-thinned foils.

\section{Acknowledgments:}

The authors would like to thank Ed Ryan, Loren Funk, Peter Baldo, and Stan Ockers of the HVEM/Tandem Facility in the Center for Electron Microscopy at Argonne National Laboratory (ANL) for their expert technical assistance in performing the irradiations. The assistance of Bernie Kestel, also of ANL in TEM sample preparation is greatly appreciated. We thank Ron Adamson of G.E. Vallecitos for furnishing the materials for this study. We acknowledge helpful discussions with K.Farrell and L.M.Howe. Luciano Pagano was supported by the Brazilian Government while pursuing his thesis research. 
Table 1 - Chemical Composition ( wt \%) of the Studied Materials

\begin{tabular}{|c|c|c|c|c|c|}
\hline Alloy & $\mathrm{Sn}$ & $\mathrm{Fe}$ & $\mathrm{Cr}$ & $\mathrm{Ni}$ & $\mathrm{Nb}$ \\
\hline Zircaloy-4 & 1.5 & 0.21 & 0.1 & $*$ & $*$ \\
\hline Zircaloy-2 & 1.6 & 0.15 & 0.1 & 0.05 & $*$ \\
\hline NSF & 1.0 & 0.2 & $*$ & 0.05 & 0.6 \\
\hline Valloy & $*$ & 0.1 & 1.1 & $*$ & $*$ \\
\hline Zr-NP & \multicolumn{3}{|c|}{ impurities less than } \\
& & & \\
\hline
\end{tabular}

* traces. Other minor constituents not reported as well. 
Figure Captions

1. (a) Concentration profile of implanted $\mathrm{Kr}$ atoms and (b) displacement profile in $\mathrm{Zr}$, after 100 $\mathrm{keV} \mathrm{Kr}$ irradiation to $2 \times 10^{16}$ ion.cm ${ }^{-2}$ as calculated by TRIM [24].

2. Bright Field TEM micrograph of recrystallized Zircaloy-4 before irradiation.

3. Bright field contrast in overfocus and underfocus conditions of bubble morphology in thin foil of Zircaloy-2 after irradiation with $100 \mathrm{keV} \mathrm{Kr}$ ions to $2 \times 10^{16}$ ion.cm ${ }^{-2}$ at $700 \mathrm{C}$. Only small bubbles, 3-5 $\mathrm{nm}$ diameter are seen.

4. Bright field contrast in overfocus condition of bubble morphology in nominally pure $\mathrm{Zr}$, after irradiation with $100 \mathrm{keV} \mathrm{Kr}$ ions to $2 \times 10^{16}$ ion.cm ${ }^{-2}$ at $500 \mathrm{C}$, under thin foil conditions. Only small bubbles, $3-5 \mathrm{~nm}$ are seen, with some evidence of bubble alignment.

5. Bright field micrographs of Zircaloy-4 irradiated with $100 \mathrm{keV} \mathrm{Kr}$ ions in bulk geometry to $2 \mathrm{x}$ $10^{16}$ ion.cm ${ }^{-2}$, at three different temperatures: (a) $300 \mathrm{C}$, (b) $500 \mathrm{C}$, (c) $700 \mathrm{C}$.

6. Bright field micrograph showing large bubbles at grain boundaries in bulk Zircaloy- 4 irradiated with $100 \mathrm{keV} \mathrm{Kr}$ ions at $700 \mathrm{C}$ to $2 \times 10^{16}$ ion. $\mathrm{cm}^{-2}$.

7. Bright field micrograph of bulk Zircaloy-4 irradiated with $100 \mathrm{keV} \mathrm{Kr}$ ions to $2 \times 10^{16}$ ion.cm ${ }^{-2}$, at $800 \mathrm{C}$. Large faceted bubbles are seen throughout the specimen. Bubble coalescence was also observed (arrowed). The precipitates seen in figure 8 are out of contrast, but their outline can be barely discerned. A higher density of small bubbles is seen within the precipitate outline ("A") rather than in-between (" $B ")$.

8. Bright field contrast of unidentified plate-like precipitates formed in bulk Zircaloy-4 after irradiation with $100 \mathrm{keV} \mathrm{Kr}$ ions to $2 \times 10^{16}$ ion. $\mathrm{cm}^{-2}$, at $800 \mathrm{C}$. 
9. Dark field contrast of precipitates in figure 8.

10. Bubble size distribution in Zircaloy-4 after irradiation with $100 \mathrm{keV} \mathrm{Kr}$ ions to $2 \times 10^{16}$ ion.cm ${ }^{-2}$, at $800 \mathrm{C}$. Two histograms are shown, one for under the precipitates, one for in-between. The zone under the precipitates has a high density of small bubbles.

11 Bright field contrast in underfocus conditions of Valloy, irradiated with $\mathrm{Kr}$ ions to $2 \times 10^{16}$ ion.cm ${ }^{-2}$, at $300 \mathrm{C}$, under thin foil conditions. Clusters of medium size bubbles (approximately 10$12 \mathrm{~nm}$ ) are seen in the arrowed regions.

12. Bubble size distribution for thin foil and bulk Zircaloy-4 at several temperatures.

13 Bubble size distribution in thin foil of various alloys irradiated at temperatures ranging from 300 to $700 \mathrm{C}$.

14. Maximum bubble diameter in Zircaloy-4 after $\mathrm{Kr}$ ion irradiation to $2 \times 10^{16}$ ion.cm $\mathrm{cm}^{-2}$ at temperatures ranging from 300 to $700 \mathrm{C}$. 


\section{References:}

1. C. Lemaignan and A. T. Motta, "Zirconium Alloys in Nuclear Applications", in Materials Science and Technology, Nuclear Materials vol 10 part B, ed B. R. T. Frost (VCH, 1994), 1-51.

2. D.Faulkner and M.P.Puls, Proc.Int.Conf. on Fundamental Aspects of Radiation Damage in Metals, Gatlingburg, TN (1975), CONF-751006-P2, 1287-1295.

3. C.D.Williams and R.W.Gilbert, Radiation Damage in Metals, IAEA, vol.1, Vienna 1969, p.235; D.O.Northwood and R.W.Gilbert, Radiation Effects, 22 (1974) 139-140.

4. A.Wolfenden and K.Farrell, Scripta Met. 6 (1972) 127-130, 7(1973), 39-42.

5. G.M.Hood, H.Zou, R.J.Schultz, J.A.Roy and J.A.Jackman, Journal of Nuclear Materials 189 (1992), 226-230.

6. Y.Adda, Proc.Conf. on Radiation Induced Voids in Metals, Albany 1971 (eds. J.W.Corbett and L.C.Ianniello), USAEC Symp.Ser.no.26, 338-362, 1972.

7. D.I.R.Norris, Radiation Effects 14 (1972) 1-37.

8. G.J.C.Carpenter, Radiation Effects, vol.11 (1973) 189-190.

9. R.W.Gilbert, K.Farrell, and C.E.Coleman, Journal of Nuclear Materials 84 (1979) 137-148.

10. A.Jostsons, P.M.Kelly, R.G.Blake and K.Farrell, ASTM STP 683, J.A.Sprague and D.Kramer, eds. (1979) 46-61.

11. M.Griffiths, R.W. Gilbert, and C.E.Coleman, J.Nucl.Mater., 159, (1988) pp. $405-416$.

12. S.N.Buckley and S.A.Manthorpe, Proc.Conf.on Physical Metallurgy of Reactor Fuel Elements, Berkeley, UK, 1973, 127-131. 
13. D.Faulkner and C.H.Woo, Journal of Nuclear Materials 90 (1980) 307-316.

14. M.Griffiths, R.C.Styles, C.H.Woo, F.Phillip and W.Frank, Journal of Nuclear Materials 208 (1994), 324-334.

15. NATO Advanced Research Workshop on Fundamental Aspects of Inert Gases in Solids, vol.279 of NATO Advanced Study Institute, Series B: Physics, ed.by S.E.Donnelly and J.H.Evans, Bonas, France 1990.

16. R.C.Birtcher and W.Jager, Ultramicroscopy 22 (1987) 267-280,

17. S.E.Donnelly and C.J.Rossouw, Nuclear Instruments and Methods in Physical Research B 13 (1986) 485-489.

18. R.C.Birtcher and A.S.Liu, Journal of Nuclear Materials, 165(1989)101-109

19. J.H.Evans and D.J.Mazey, J.Phys.F: Met.Phys. 15 (1985) L1-L6.

20. J.H.Evans and D.J.Mazey, Journal of Nuclear Materials, 138 (1986) 176-184.

21. J.H.Evans and D.J.Mazey, Scripta Met. 19 (1985) 621-623.

22. D.J.Mazey and J.H.Evans, Journal of Nuclear Materials 138 (1986) 16-18.

23. B.Kestel, Ultramicroscopy 19 (9186) 205.

24. J.F.Ziegler, J.P.Biersack and U.Littmark, "The Stopping and Range of Ions in Solids", Pergamon Press, New York, 1985.

25. C.Ronchi, Journal of Nuclear Materials, 96 (1981) 314-328.

26. D.Kaletta, Radiation Effects, vol.78 (1983) 245-259. 
$\mathrm{Kr}$ concentration (atom \%)

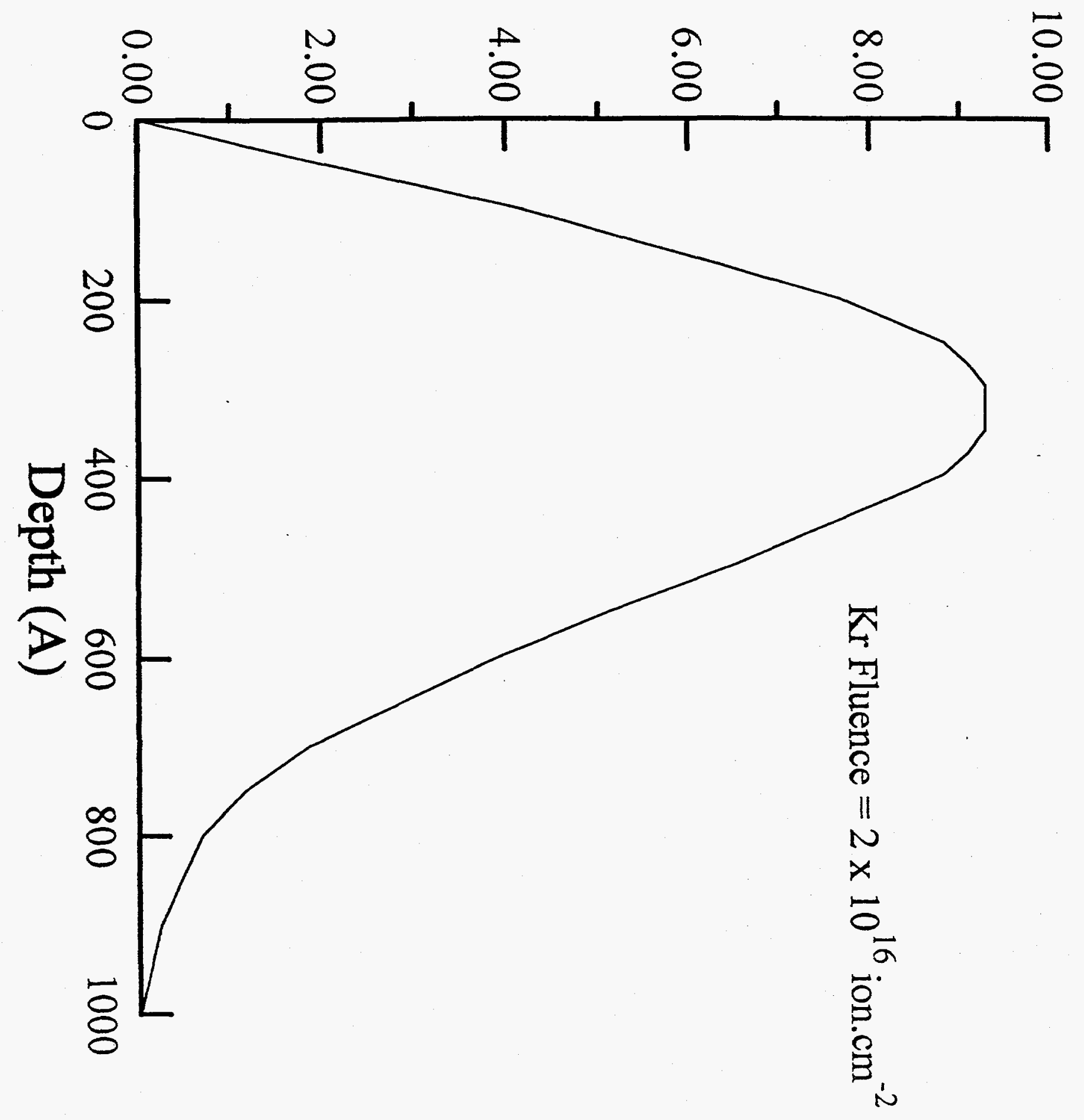

-71

4

p 


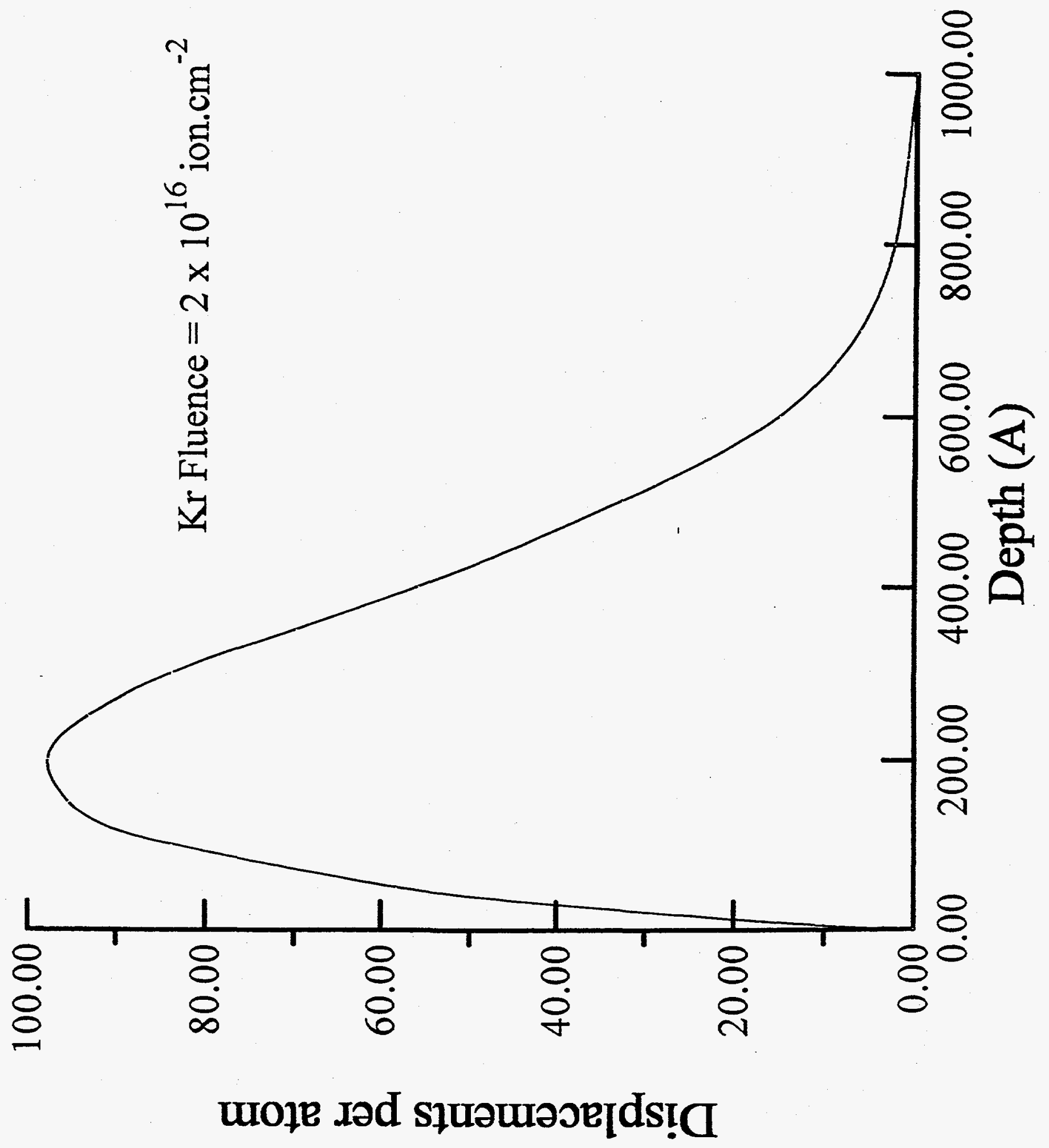



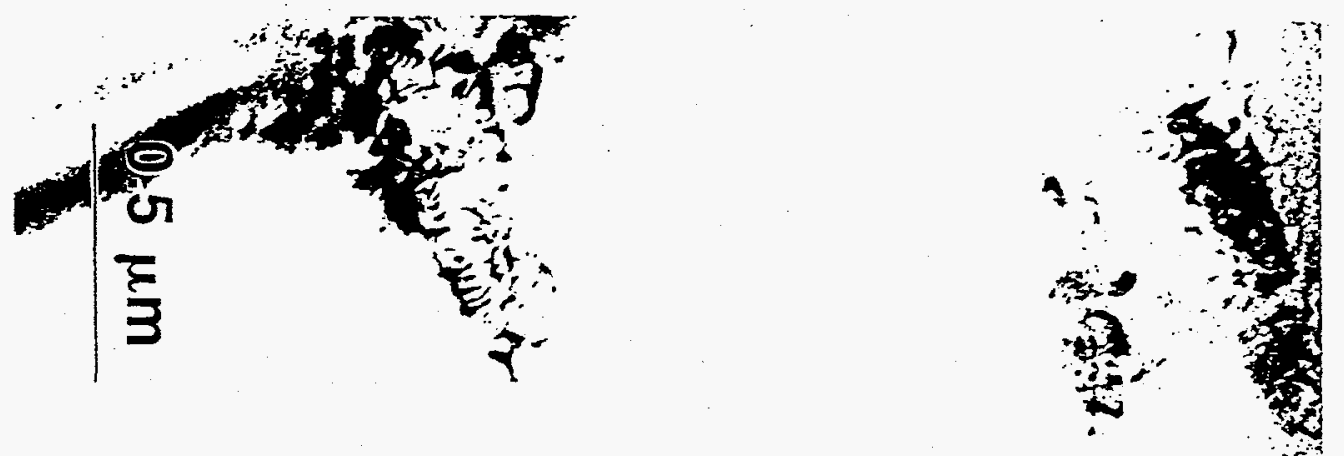

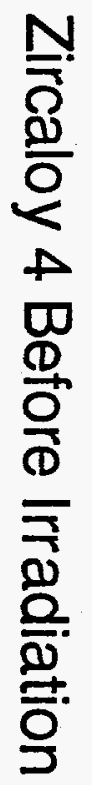

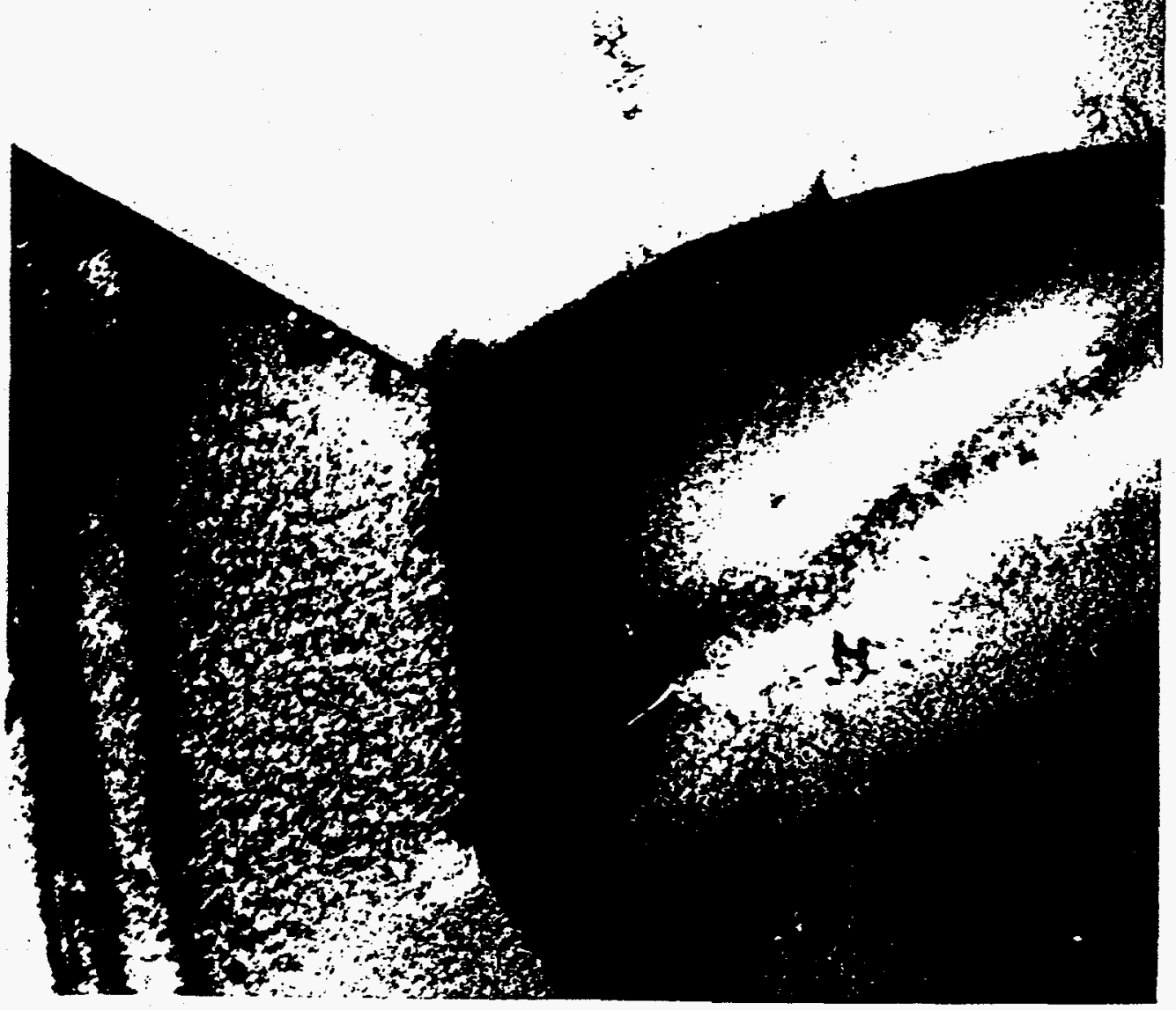

$\frac{\pi}{6}$ 

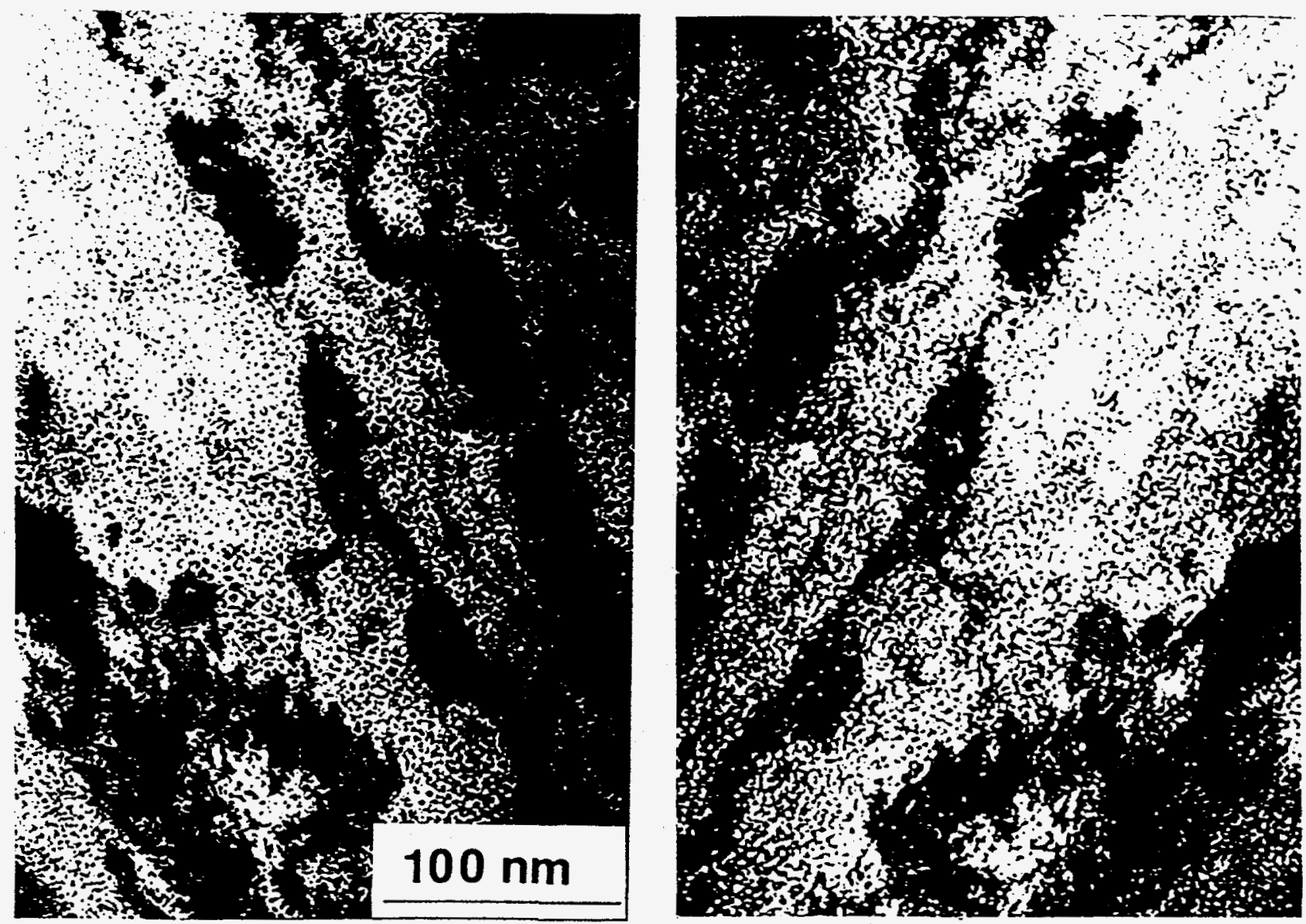


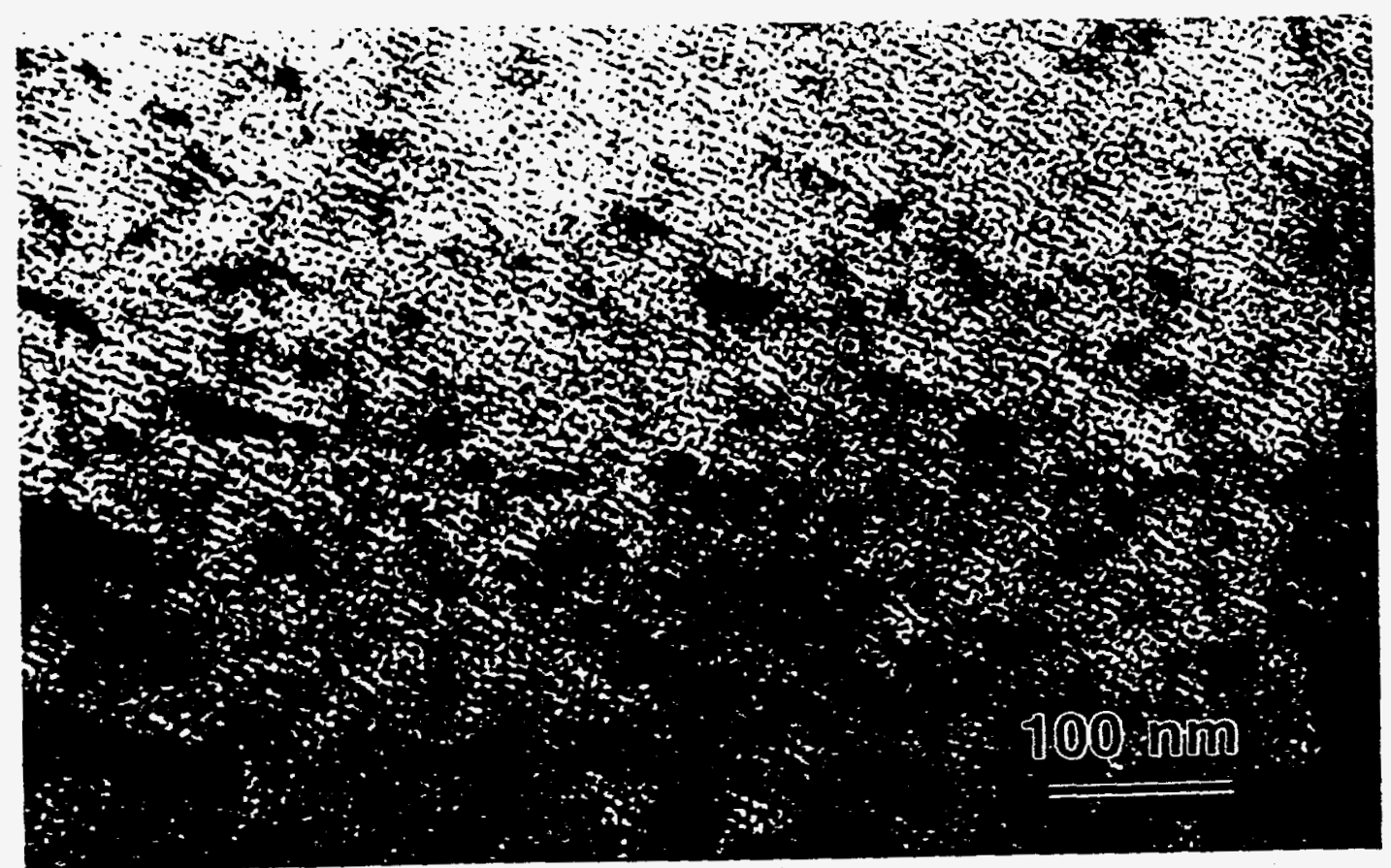



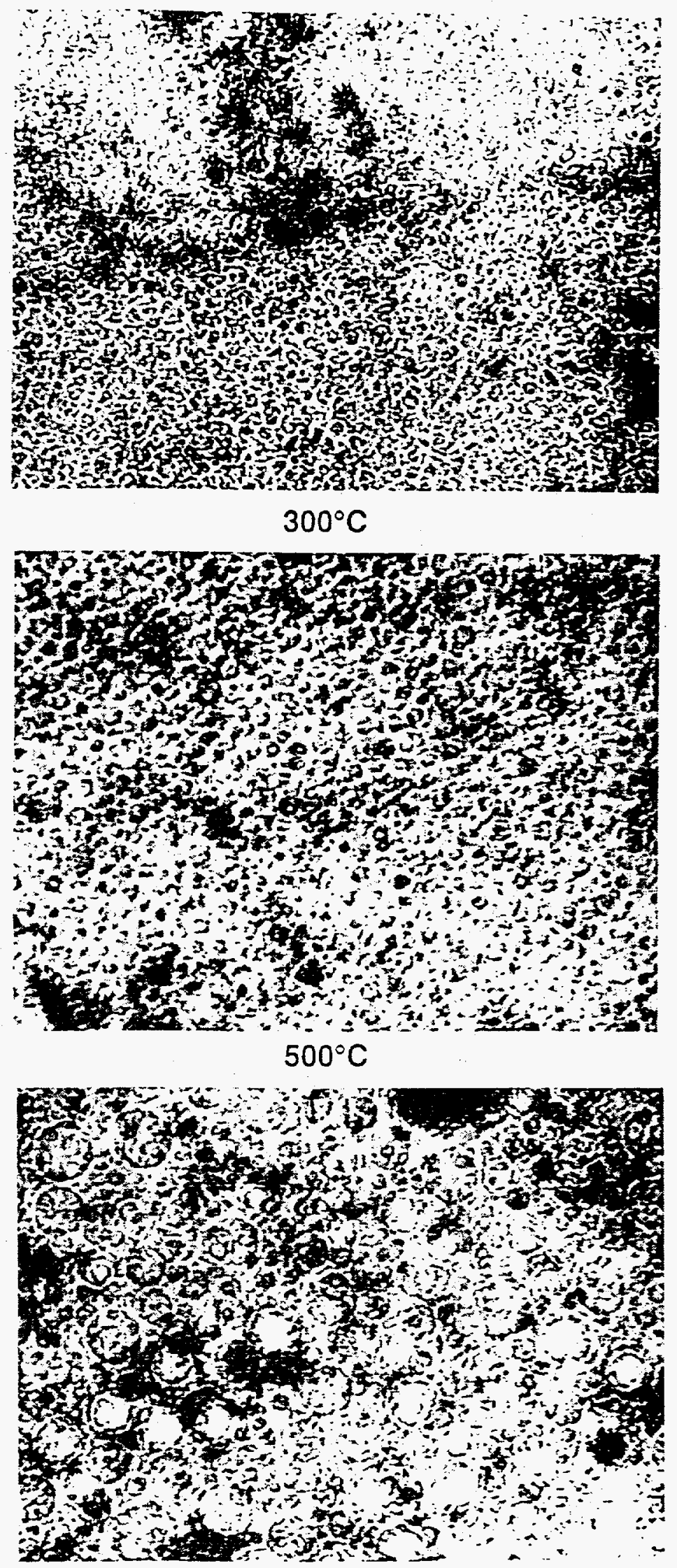

$700^{\circ} \mathrm{C}$

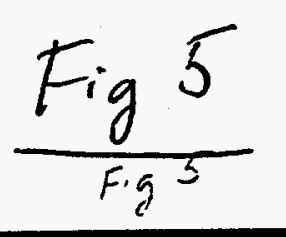




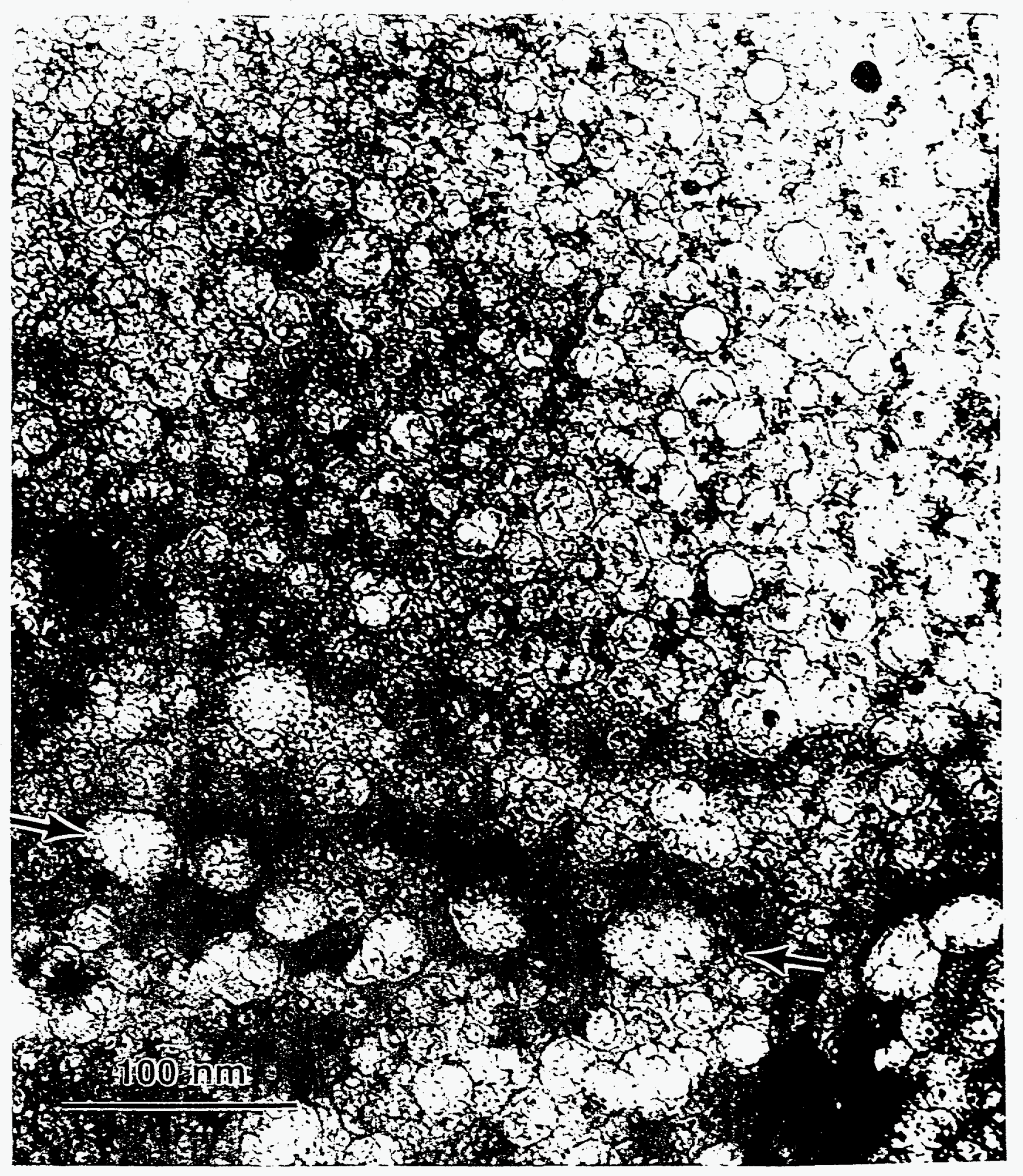









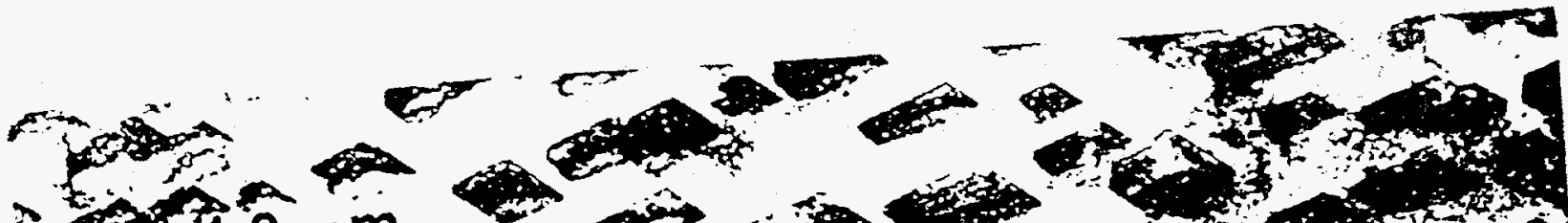

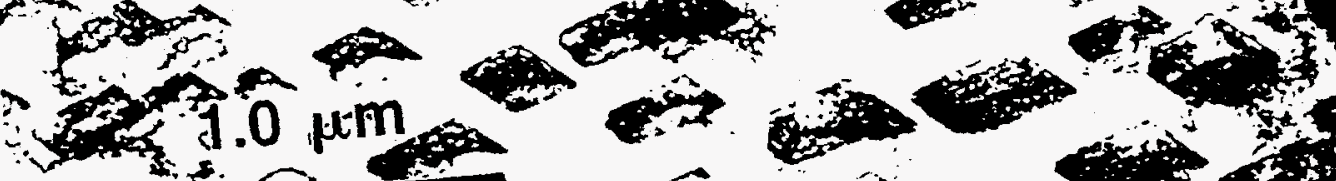

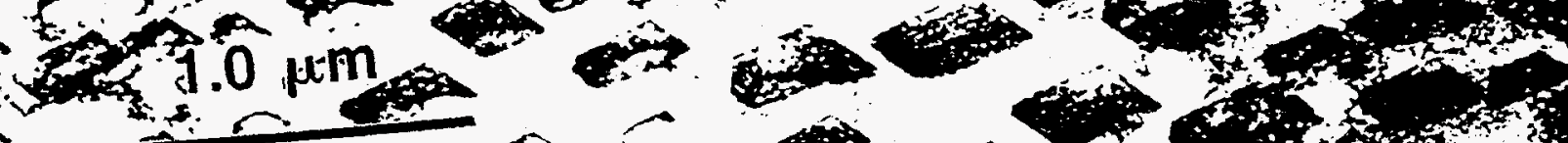

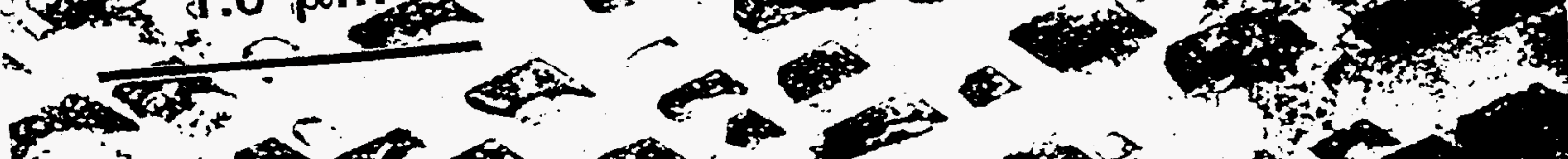

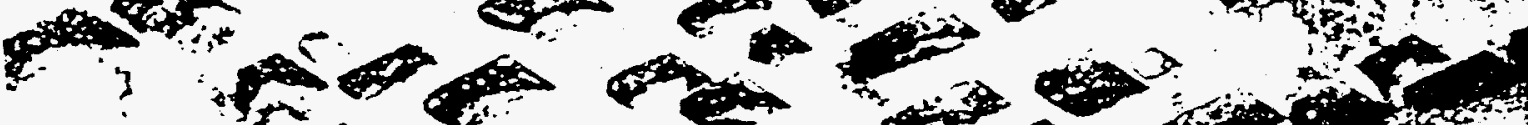
ta p.

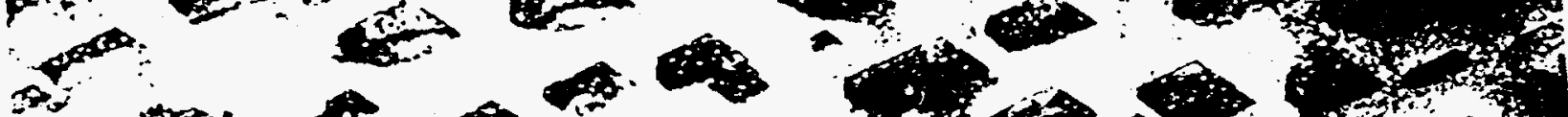

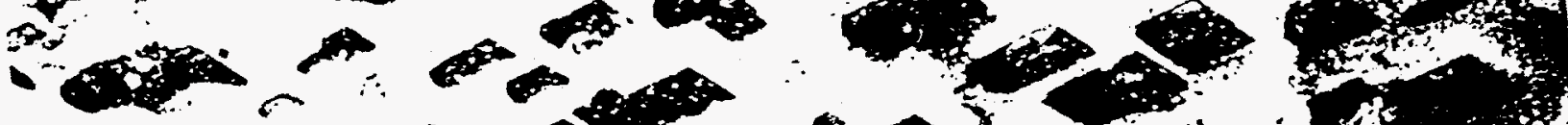

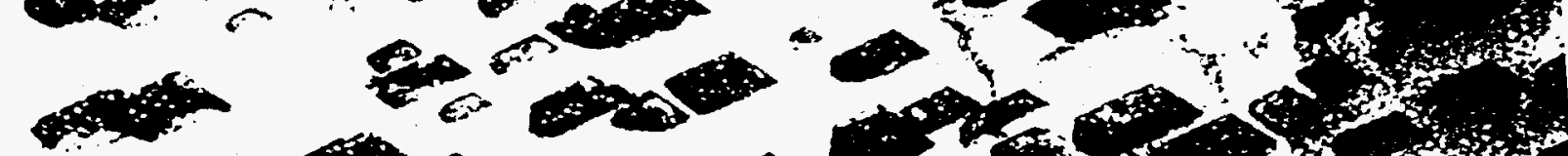

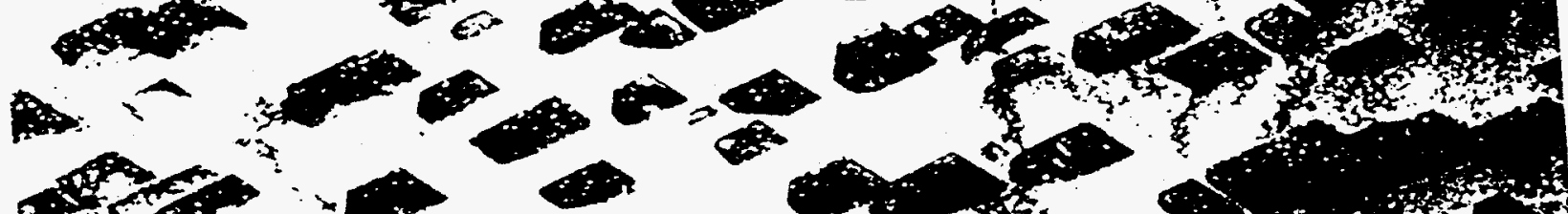
30

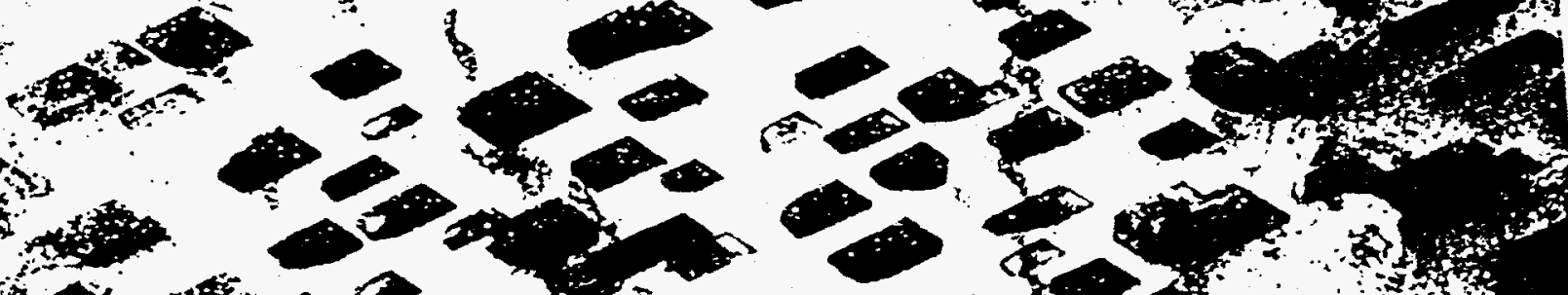

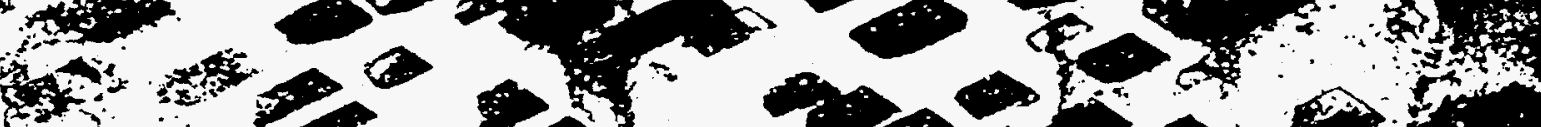
SA

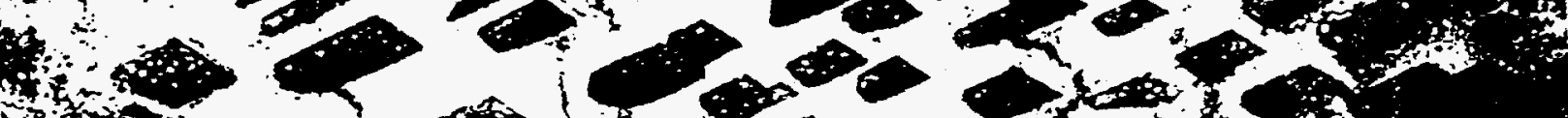
Yjow (f)

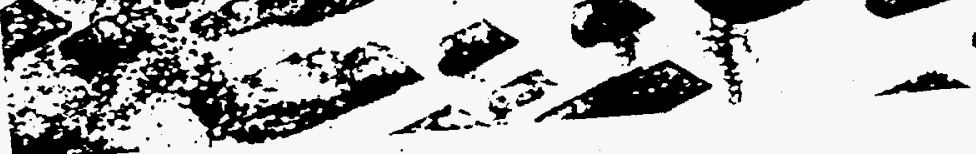




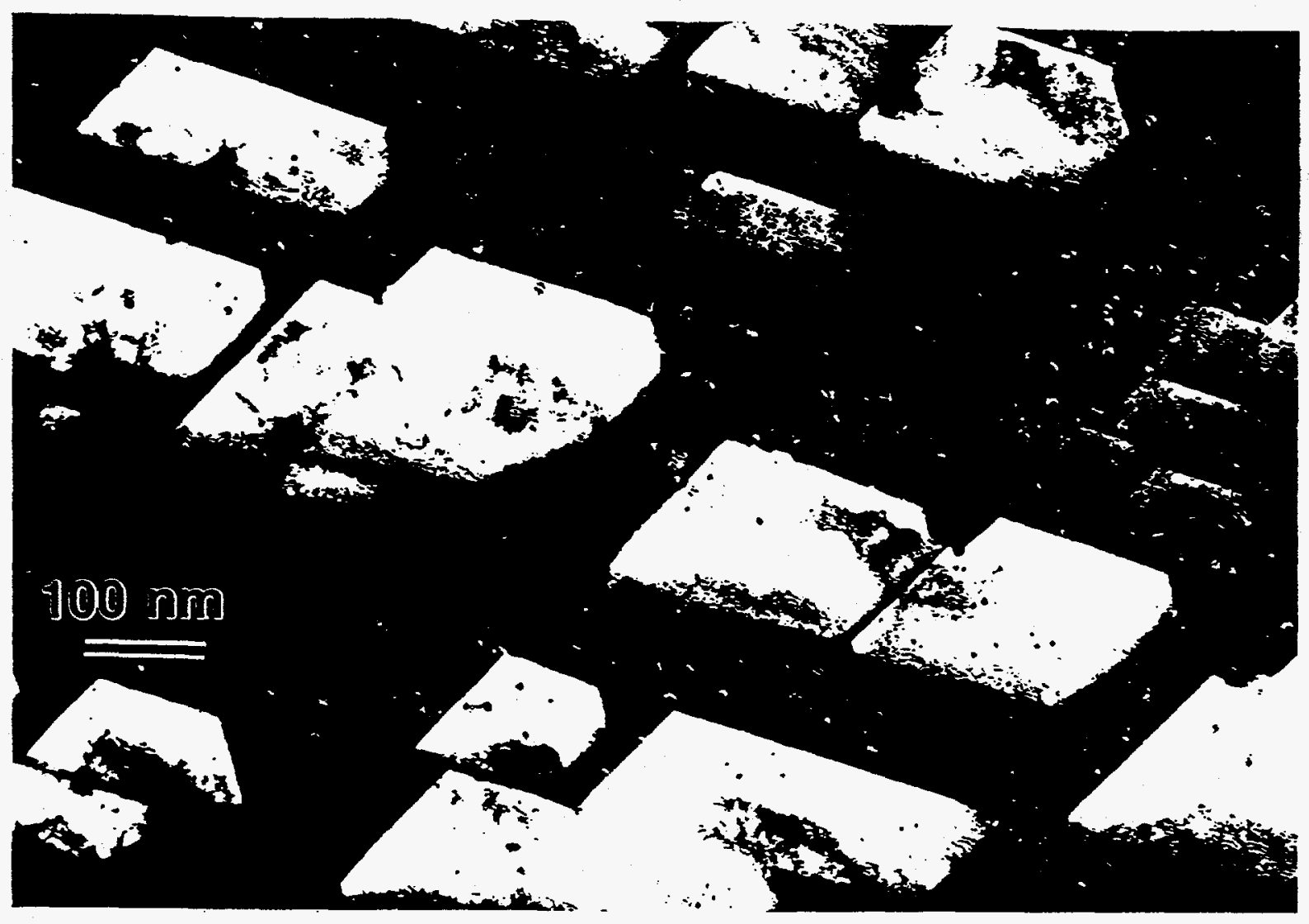

Fig 9 


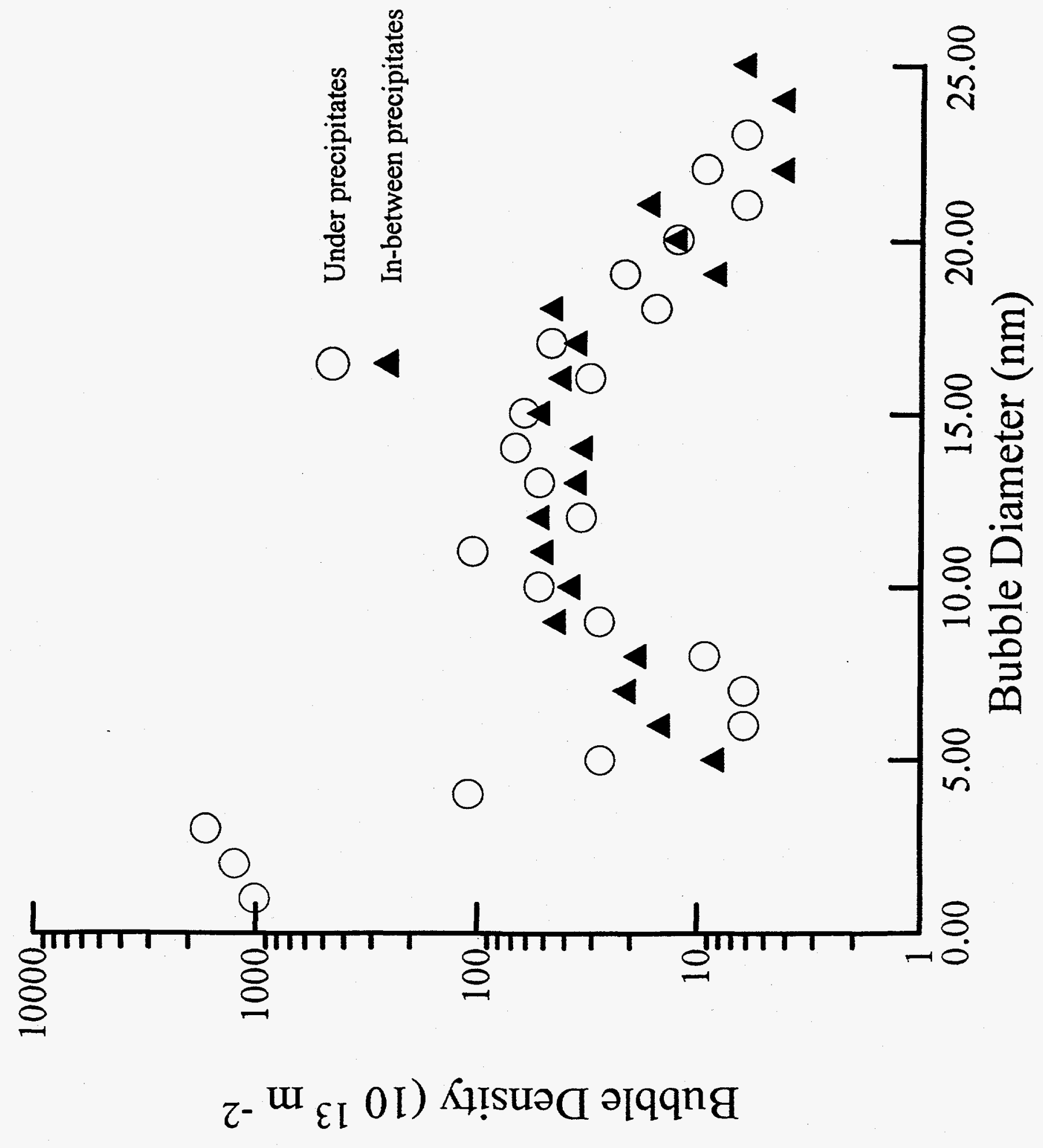




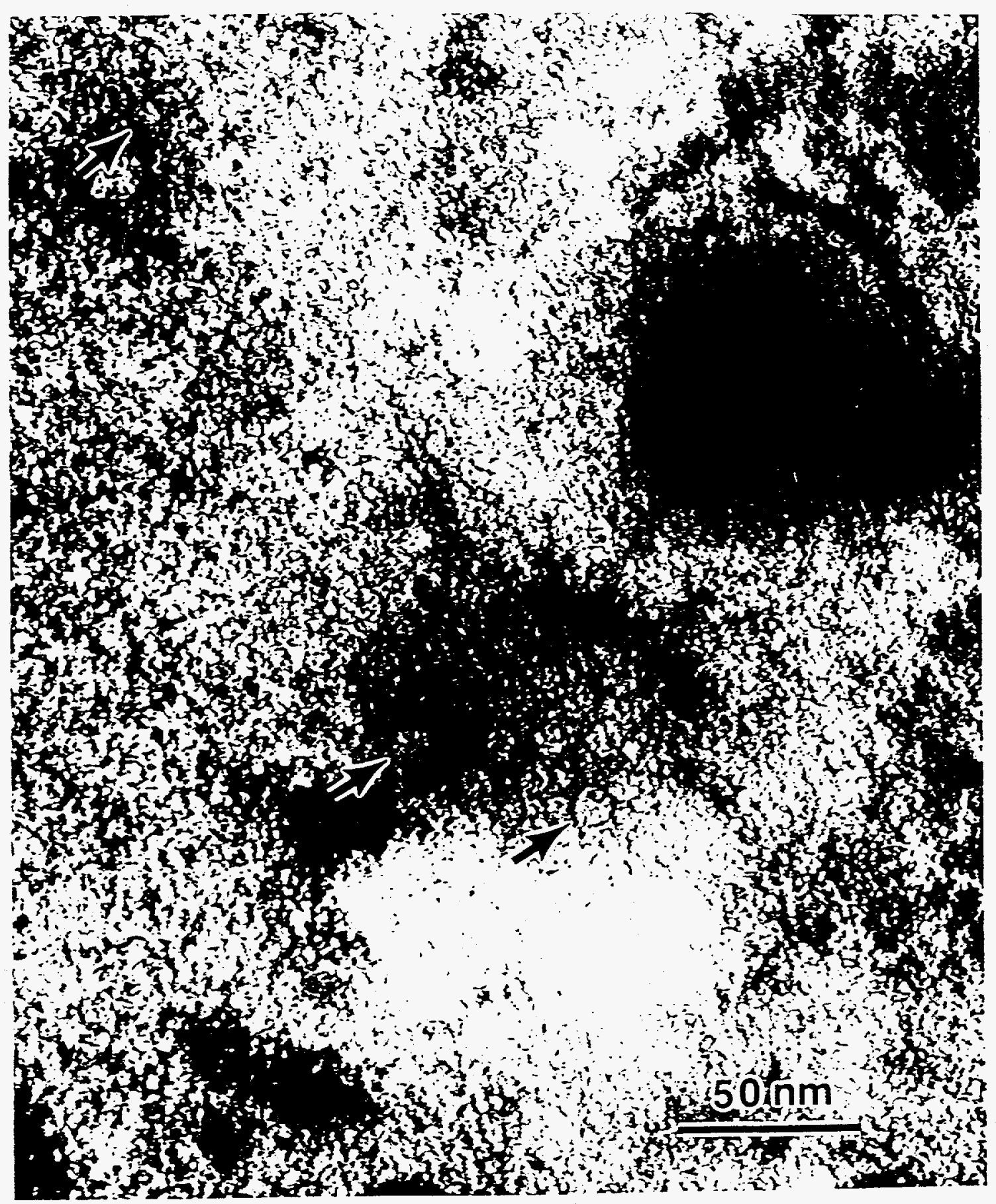




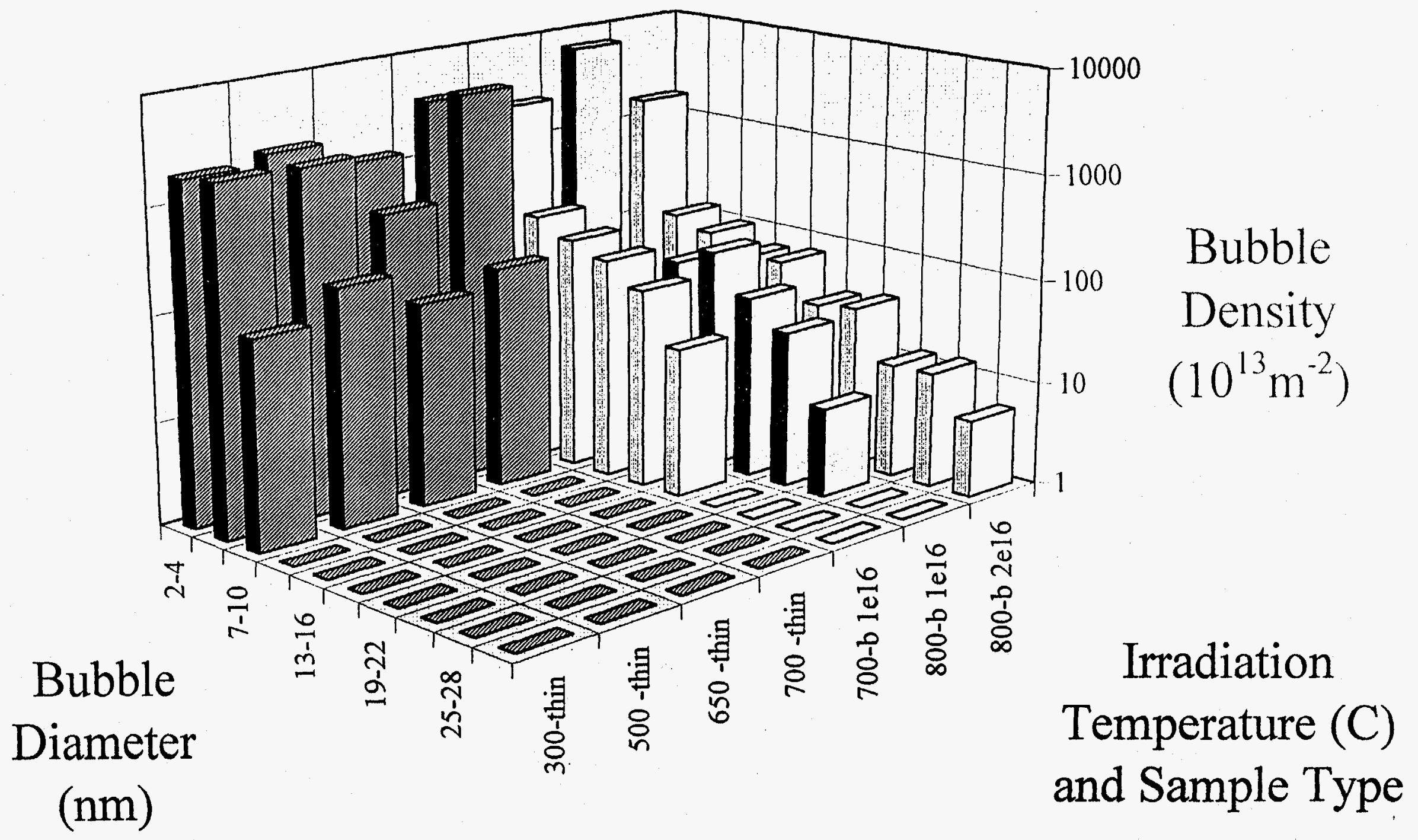

Fig 12 
$4+1$

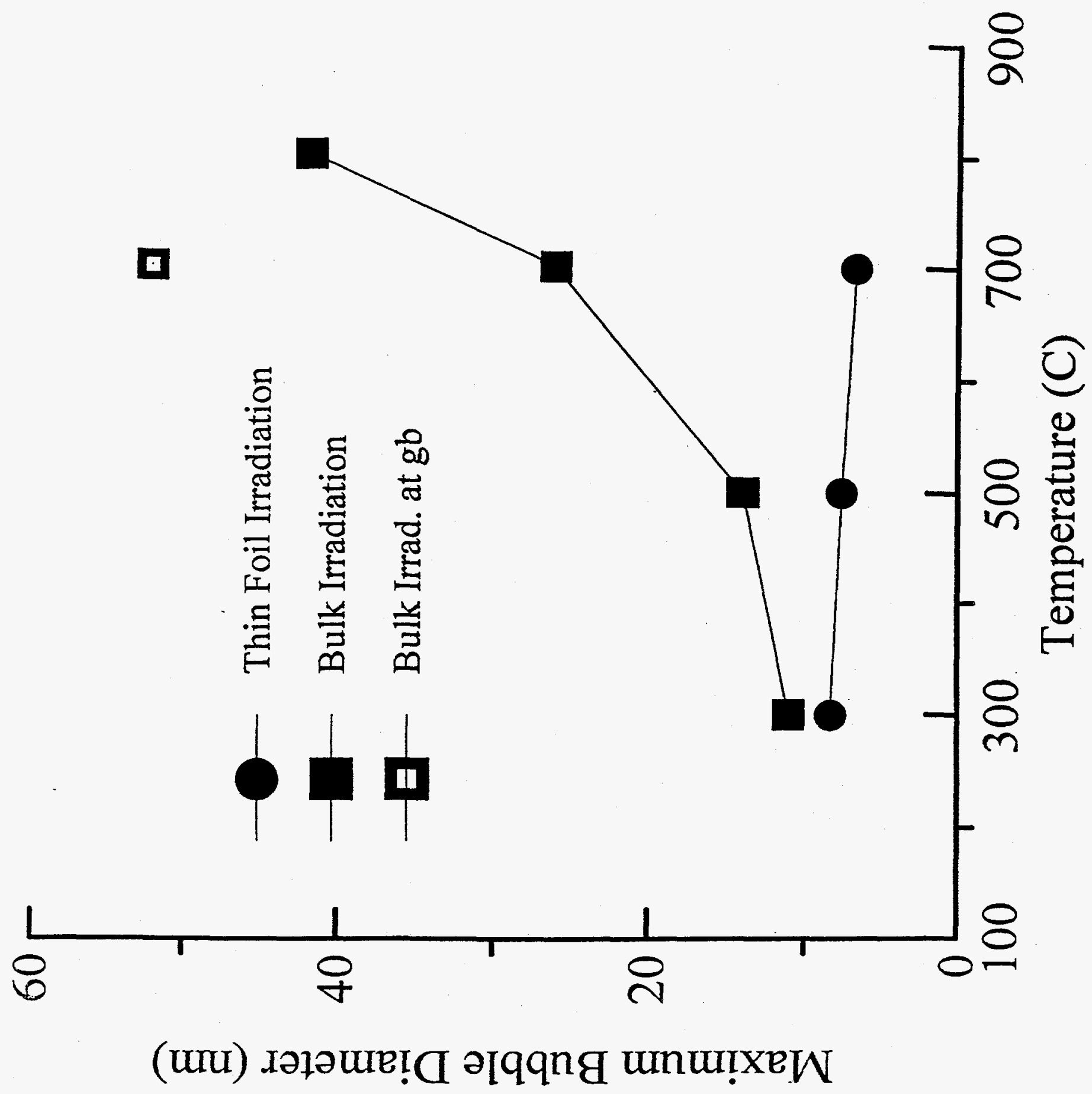

Fig 13 